\title{
PENGETAHUAN ANAK TENTANG MENYIKAT GIGI YANG BAIK TERHADAP HALITOSIS PADA SISWA-SISWI KELAS IV SD SWASTA ST. IGNATIUS MEDAN JOHOR
}

\author{
Susy Adrianelly Simaremare \\ Jurusan Keperawatan Gigi
}

\begin{abstract}
ABSTRAK
Menyikat gigi bertujuan untuk membuang plak sebersih mungkin, sebab di dalam plak inilah kuman paling banyak tinggal. Plak adalah suatu lapisan lunak yang terdiri dari kumpulan mikroorganisme yang berkembang biak diatas suatu matriks yang terbentuk dan melekat erat pada permukaan gigi. Halitosis merupakan bau mulut tidak sedap yang keluar dari mulut akibat kurang menjaga kebersihan gigi dan mulut dan dapat melibatkan kesehatan dan kehidupan sosial seseorang. Penelitian ini bertujuan untuk mengetahui gambaran pengetahuan anak tentang menyikat gigi yang baik terhadap halitosis pada siswa-siswi kelas IV SD Swasta St.Ignatius Medan Johor. Jenis penelitian yang digunakan adalah penelitian deskriptif dengan metode survey. Penelitian dilakukan pada anak kelas IV SD Swasta St. Ignatius Medan Johor dengan jumlah sampel sebanyak 20 orang. Hasil penelitian menunjukkan gambaran pengetahuan anak tentang cara menyikat gigi yang baik terhadap halitosis, siswa-siswi yang memiliki kriteria baik ada 6 orang, kriteria sedang ada 12 orang dan yang memiliki kriteria buruk ada 2 orang. Berdasarkan tabel frekuensi pengetahuan anak tentang waktu menyikat gigi yang baik terhadap halitosis, siswa-siswi kelas IV SD Swasta St.Ignatius Medan yang memiliki kriteria baik ada 2 orang, 17 orang memiliki kriteria sedang dan 1 orang memiliki kriteria buruk. Kesimpulannya, bahwa pengetahuan anak tentang menyikat gigi yang baik meliputi cara, waktu dan frekuensi menyikat gigi yang baik itu mempengaruhi halitosis seorang anak. Untuk itu, diharapkan kepada tenaga kesehatan khususnya gigi untuk lebih meningkatkan penyuluhan kesehatan gigi.
\end{abstract}

Kata kunci

: Menyikat Gigi, Plak, Halitosis

\section{LATAR BELAKANG}

Kesehatan merupakan bagian yang sangat penting bagi kehidupan manusia. Menurut Undang-Undang Pokok Kesehatan, "Sehat adalah suatu keadaan sempurna yang meliputi kesehatan badan (fisik), rohani (mental), sosial dan bukan hanya keadaan yang bebas dari penyakit, cacat atau kelemahan. Untuk mencapai kesehatan yang maksimal pemerintah mencanangkan program pembangunan nasional yang bertujuan untuk mengubah prilaku masyarakat ke arah perilaku sehat.

Menyikat gigi adalah cara yang umum digunakan untuk membersihkan berbagai kotoran yang melekat di permukaan gigi dan gusi. Menyikat gigi bertujuan untuk memelihara kebersihan gigi dan mulut terutama gigi serta jaringan sekitarnya.

Keadaan gigi dan rongga mulut yang tidak sehat selain dapat menyebabkan keluhan penyakit gigi dan mulut juga dapat menimbulkan bau mulut yang tidak sedap atau yang disebut halitosis. Halitosis dapat menghambat dan menyebabkan pengucilan sosial. Hal ini sering terjadi pada orang-orang yang dalam pekerjaannya lebih banyak berhubungan dengan publik, sehingga mereka harus tetap menjaga kebersihan serta kesehatan mulutnya agar terhindar dari bau mulut yang tidak menyenangkan yang mengurangi keyakinan dan rasa percaya diri. Halitosis merupakan salah satu masalah yang paling umum.
Kekurangan vitamin B6 juga dapat menyebabkan bau mulut tidak enak. Juga bagi orang penderita seperti diabetes mellitus menyebarkan bau khas yang kurang sedap. Apalagi yang berhubungan dengan jalan nafas, seperti penyakit paru-paru, jalan nafas, dan lain-lain. Keadaan bau mulut yang tidak sedap juga berhubungan erat dengan daerah telinga, hidung,dan tenggorokan.

Oleh karena itu, penulis merasa perlu untuk meninjau lebih lanjut mengenai halitosis ini. Berdasarkan latar belakang diatas, penulis tertarik untuk melakukan penelitian pada siswa-siswi kelas IV SD Swasta St. Ignatius tentang Gambaran Pengetahuan Anak tentang Menyikat Gigi yang Baik Terhadap Halitosis pada siswasiswi kelas IV SD Swasta St. Ignatius Kecamatan Medan Johor.

\section{PERUMUSAN MASALAH}

Berdasarkan latar belakang, maka perumusan masalah adalah bagaimana gambaran pengetahuan anak tentang menyikat gigi terhadap halitosis pada siswa-siswi kelas IV SD Swasta St. Ignatius Kecamatan Medan Johor.

\section{TUJUAN PENELITIAN}

Penelitian ini dilakukan bertujuan untuk mengetahui gambaran pengetahuan anak tentang menyikat 
gigi yang baik terhadap halitosis pada siswa-siswi kelas IV SD Swasta St. Ignatius Kecamatan Medan Johor.

\section{MANFAAT PENELITIAN}

1. Sebagai masukan atau informasi pada siswa-siswi kelas IV SD Swasta St. Ignatius tentang menyikat gigi yang baik, yaitu mengetahui cara, waktu dan frekuensi menyikat gigi yang baik terhadap halitosis.

2. Menjadi masukan bagi pihak sekolah dalam melaksanakan program Upaya Kesehatan Gigi Sekolah.

3. Sebagai bahan masukan dan sumber pengetahuan bagi peneliti selanjutnya.

\section{Kerangka Konsep}

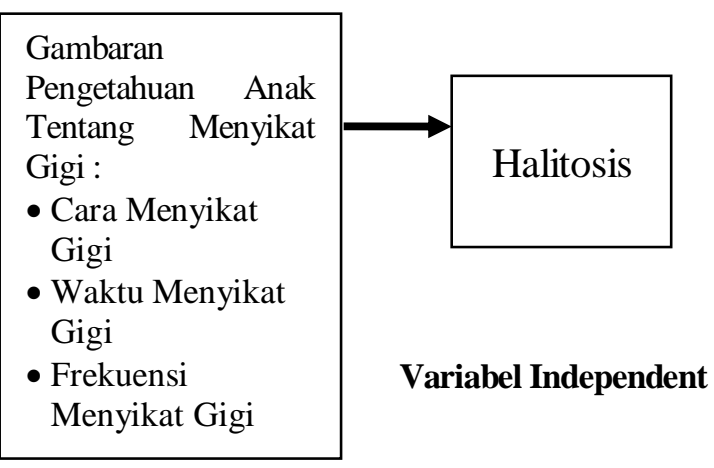

\section{Defenisi Operasional}

Untuk mencapai tujuan yang ingin dicapai dalam penelitian ini penulis menentukan defenisi operasional sebagai berikut :

1. Gambaran Pengetahuan menyikat gigi adalah kemampuan yang dimiliki siswa-siswi kelas IV SD Swasta St. Ignatius tentang menyikat gigi yang baik , meliputi cara,waktu dan frekuensi.

2. Cara menyikat gigi adalah pengetahuan siswa-siswi kelas IV SD Swasta St. Ignatius tentang cara untuk menjaga kebersihan gigi dan mulut dengan menggunakan sikat gigi .

3. Waktu Menyikat Gigi adalah waktu yang tepat dilakukan siswa-siswi kelas IV SD Swasta St. Ignatius dalam menyikat gigi yaitu pagi sesudah sarapan dan malam sebelum tidur.

4. Frekuensi menyikat gigi adalah frekuensi yang tepat dilakukan siswa-siswi kelas IV SD Swasta St. Ignatius dalam menyikat gigi yaitu 2 kali dalam sehari.

5. Halitosis adalah bau tidak sedap yang muncul dari mulut akibat tidak menjaga kebersihan mulut.

\section{Jenis dan Desain Penelitian}

Jenis penelitian yang dilakukan adalah deskriptif dengan metode survey, yang bertujuan untuk mengetahui gambaran pengetahuan anak tentang menyikat gigi yang baik terhadap halitosis pada siswa-siswi kelas IV SD Swasta St. Ignatius Kecamatan Medan Johor.

\section{Lokasi Penelitian}

Lokasi penelitian adalah SD Swasta St. Ignatius Kecamatan Medan Johor .

\section{Populasi}

Populasi adalah keseluruhan objek peneliti atau objek yang diteliti. (Notoatmodjo, 2005). Populasi yang diambil dalam penelitian ini adalah seluruh anak kelas IV SD Swasta St. Ignatius Kecamatan Medan Johor yang berjumlah 20 orang.

Sampel

Sampel dalam penelitian ini adalah total keseluruhan populasi yang berjumlah 20 orang.

\section{Jenis dan Cara Pengumpulan Data}

Jenis data yang diambil dalam penelitian ini adalah data primer yang dilakukan dengan menggunakan kuesioner langsung. Data langsung diambil oleh peneliti beserta tim ke lokasi penelitian yaitu SD Swasta St. Ignatius Kecamatan Medan Johor.

Untuk menentukan interval dari nilai yang terdapat dalam kriteria penilaian tersebut digunakan rumus : Interval $=\underline{\text { Nilai maksimal }- \text { nilai minimal }}$

\section{Kriteria Penilaian}

Sehingga nilai dalam kriteria penelitian tersebut adalah :

- Baik : nilai berada 5-6

- Sedang : nilai berada diantara 3-4

- Buruk : nilai berada diantara 1-2

\section{Pengolahan Data dan Analisa Data}

Semua data yang telah terkumpul dari pengisian kuesioner diolah dengan melakukan editing, koding dan tabulating. Setelah itu diambil kesimpulan dari hasil pengolahan data tersebut.

Analisa Data

Data yang terkumpul dianalisa dengan langkah-langkah sebagai berikut:

1. Mengumpulkan hasil kuesioner serta menghitung jumlahnya sesuai dengan jumlah siswa-siswi kelas IV SD Swasta St.Ignatius.

2. Mencocokkan jawaban setiap siswa-siswi dengan kunci jawaban.

3. Memberikan nilai pada jawaban yang benar bernilai 1 dan salah bernilai 0 .

4. Memberikan kriteria berdasarkan nilai yang didapatkan.

\section{HASIL DAN PEMBAHASAN}

Pengetahuan anak tentang menyikat gigi yang baik terhadap halitosis pada siswa-siswi kelas IV SD Swasta St. Ignatius Medan dapat dilihat pada tabel 1. 
Tabel 1. Distribusi Frekuensi Karakteristik Anak

\begin{tabular}{|l|l|l|}
\hline Karakteristik Anak & $\begin{array}{l}\text { Sampel } \\
(\mathrm{n})\end{array}$ & $\begin{array}{l}\text { Persentase } \\
(\%)\end{array}$ \\
\hline - Jenis Kelamin : & 10 & 50 \\
- Laki-laki & 10 & 50 \\
\hline - Perempuan & Umur : & 10 \\
-8 tahun & 2 & 90 \\
-9 tahun & 18 & \\
\hline
\end{tabular}

Dari tabel diatas, diketahui bahwa siswa-siswi kelas IV SD Swasta St. Ignatius Medan Johor yang berumur 9 tahun ada sebanyak 18 orang anak (90\%). Juga terdapat 2 orang anak (10\%) yang berumur 8 tahun. Anak yang berjenis kelamin laki-laki dan perempuan masingmasing ada 10 orang dengan persentase karakteristik anak senilai $50 \%$ untuk kedua jenis kelamin.

Tabel 2. Distribusi Frekuensi Pengetahuan Anak tentang Pengetahuan Menyikat Gigi yang Baik Terhadap Halitosis pada siswa-siswi kelas IV SD Swasta St.Ignatius Medan Johor.

Dari tabel diatas, diketahui bahwa pengetahuan anak tentang cara menyikat gigi yaitu 6 orang $(30 \%)$ memiliki pengetahuan cara menyikat gigi dengan kriteria baik, 12 orang $(60 \%)$ memiliki pengetahuan cara menyikat gigi yang baik dengan kriteria sedang dan 2 orang $(10 \%)$ memiliki kriteria buruk terhadap pengetahuan cara menyikat gigi yang baik.

Data pengetahuan anak tentang waktu menyikat gigi yang baik, terlihat 2 orang anak (10\%) memiliki pengetahuan dengan kriteria baik, 17 orang (85\%) memiliki pengetahuan dengan kriteria sedang dan ada 1 orang $(5 \%)$ memiliki pengetahuan tentang waktu menyikat gigi yang baik dengan kriteria buruk.

Data pengetahuan anak tentang frekuensi menyikat gigi yang baik, terlihat 6 orang $(30 \%)$ memiliki kriteria baik, 12 orang $(60 \%)$ memiliki pengetahuan sedang dan ada 2 orang anak (10\%) yang memiliki pengetahuan buruk tentang pengetahuan frekuensi menyikat gigi yang baik.

\section{PEMBAHASAN}

Dari tabel 1 diatas, diketahui siswa-siswi kelas IV SD Swasta St. Ignatius Medan Johor yang memiliki pengetahuan tentang cara menyikat gigi adalah : ada 6 siswa-siswi (30\%) memiliki pengetahuan baik tentang cara menyikat gigi, sedangkan 12 orang $(60 \%)$ siswa-siswi lainnya memiliki pengetahuan sedang dan ada 2 orang (10\%) yang tidak memiliki pengetahuan tentang cara menyikat gigi yang terhadap halitosis.

Menurut Aziz Ahmad Srigupta (2004), cara menyikat gigi yang benar adalah menyikat dengan gerakan pendek-pendek, dan untuk menyikat gigi bagian atas jangan ke atas begitu juga dengan bagian bawah; hal ini untuk menghindari agar gusi tidak terkelupas. Tetapi bulu sikat harus dikenakan pada gusi, agar gusi terpijat oleh bulu-bulu halus sikat gigi. Untuk menyikat permukaan samping baik luar maupun dalam jangan melawan arah permukaan gusi (ujung pinggir gusi).

\begin{tabular}{|c|c|c|c|c|c|c|}
\hline \multirow{3}{*}{ Kriteria } & \multicolumn{5}{|c|}{$\begin{array}{c}\text { Pengetahuan Anak Tentang } \\
\text { Menyikat Gigi }\end{array}$} \\
\cline { 2 - 7 } & \multicolumn{2}{|c|}{ Cara } & \multicolumn{2}{c|}{ Waktu } & \multicolumn{2}{c|}{ Frekuensi } \\
\cline { 2 - 7 } & $\mathrm{n}$ & $\%$ & $\mathrm{n}$ & $\%$ & $\mathrm{n}$ & $\%$ \\
\hline Baik & 6 & 30 & 2 & 10 & 6 & 30 \\
\hline Sedang & 12 & 60 & 17 & 85 & 12 & 60 \\
\hline Buruk & 2 & 10 & 1 & 5 & 2 & 10 \\
\hline Jumlah & 20 & 100 & 20 & 100 & 20 & 100 \\
\hline
\end{tabular}

Berdasarkan tabel 2, diperoleh data pengetahuan anak tentang cara, waktu dan frekuensi menyikat gigi yang baik. Pada data pengetahuan anak tentang cara menyikat gigi yang baik, terlihat 6 orang anak (30\%) memiliki kriteria baik, 12 orang (60\%) memiliki kriteria sedang dan ada 2 orang anak $(10 \%)$ memiliki kriteria pengetahuan yang buruk tentang cara menyikat gigi. Pada data pengetahuan anak tentang waktu menyikat gigi yang baik, diketahui 2 orang (10\%) memiliki kriteria baik, 17 orang (85\%) memiliki kriteria sedang dan terdapat 1 anak (5\%) memiliki kriteria buruk. Pada data pengetahuan anak tentang frekuensi menyikat gigi yang baik, terlihat 6 orang anak (30\%) memiliki kriteria baik, 12 orang anak $(60 \%)$ memiliki kriteria sedang dan ada 2 orang anak (10\%) memiliki kriteria buruk.

Menurut (Panjaitan, 1995) waktu dan frekuensi menyikat gigi yang baik adalah segera sesudah makan atau paling lambat 10 menit sesudah makan, hal ini besar manfaatnya untuk mencegah timbulnya plak. Lamanya menyikat gigi dianjurkan minimal lima menit, tetapi umumnya orang menyikat maksimum selama 2-3 menit. Tetapi, hal ini tidak dapat menjadi patokan berhasil atau tidaknya seseorang dalam menyikat gigi, hal ini masih bergantung pada cara-cara menyikat gigi, bentuk sikat gigi serta waktu menyikat gigi.

\section{Kesimpulan}

1. Jumlah siswa-siswi kelas IV SD Swasta St. Ignatius yang memiliki pengetahuan cara menyikat gigi yang baik terhadap halitosis dengan kriteria baik ada 6 orang (30\%), kriteria sedang sebanyak 12 orang $(60 \%)$, dan kriteria buruk sebanyak 2 orang (10\%).

2. Jumlah siswa-siswi kelas IV SD Swasta St. Ignatius yang memiliki pengetahuan waktu menyikat gigi yang baik terhadap halitosis dengan kriteria baik ada 2 orang (10\%), 17 orang $(85 \%)$ memiliki kriteria sedang dan ada 1 orang $(5 \%)$ memiliki kriteria buruk..

3. Jumlah siswa-siswi kelas IV SD Swasta St. Ignatius yang memiliki pengetahuan frekuensi menyikat gigi yang baik terhadap halitosis dengan kriteria baik adalah 6 orang (30\%), 12 orang (60\%) memiliki kriteria sedang, dan ada 2 orang anak $(10 \%)$ memiliki kriteria buruk. 


\section{Saran}

a. Hendaknya siswa-siswi dapat menyikat gigi dengan baik (cara, waktu dan frekuensi) agar terhindar dari halitosis.

b. Kepada orangtua murid hendaknya senantiasa mengawasi anak untuk menyikat gigi secara benar.

c. Diharapkan kepada pihak SD Swasta St. Ignatius Medan Johor agar tetap bekerjasama dengan Puskesmas setempat untuk menjalankan kegiatan Upaya Kesehatan Gigi Sekolah sebagai upaya peningkatan kesehatan gigi anak.

\section{DAFTAR PUSTAKA}

Herjulianti Eliza, 2002, Pendidikan Kesehatan Gigi, Penerbit Buku Kedokteran EGC, Jakarta.

Machfoedz Ircham, 2008, Menjaga Kesehatan Gigi \& Mulut Anak-anak dan Ibu Hamil, Penerbit Fitramaya, Yogyakarta.

Notoatmodjo Soekidjo, 2005, Metodologi Penelitian Kesehatan, PT. Rineka Cipta, Jakarta.
Panjaitan Monang, 1995, Etiologi Karies Gigi dan Penyakit Periodontal, Penerbit Universitas Sumatera Utara Press, Medan.

Pintauli Sondang, 2010, Menuju Gigi \& Mulut Sehat, Universitas Sumatera Utara Press, Medan.

Srigupta Aziz Ahmad, 2004, Perawatan Gigi \& Mulut, Prestasi Pustaka Publisher, Jakarta.

Sriyono Niken Widyanti, 2005, Ilmu Kedokteran Gigi Pencegahan, Medika Fakultas Kedokteran UGM, Yogyakarta.

http://databerita.com/cara-sikat-gigi-yang-baik-benar/

http://bz.blogfam.com/2006/03/menyikat gigi_bagi_anak. html

http://ustadchandra.wordpress.com/2011/03/16/gigi-muluthalitosis-bau-mulut/ 